\title{
OS OBJETOS NO TEATRO
}

\section{OBJECTS IN THEATRE}

\author{
Gilvamberto Felix \\ gilvambertocomunidade@hotmail.com \\ UNIVERSIDADE FEDERAL DO CEARÁ - UFC
}

\section{Resumo:}

A relação entre teatro e os objetos já marcam longas datas e as abordagens são bastante distintas no que diz respeito ao diálogo entre estes dois elementos. Pautado na diversidade de utilizações indaga-se qual objeto é válido para o teatro. Traçando um percurso que envolve a investigação das potencialidades pedagógicas e criativas dos objetos no teatro, as questões aqui apresentadas perpassam a percepção de alunos de teatro do ensino médio e as acepções de Patrice Pavis, Fernando Stratico, Ligia Clark e outros autores a cerca do tema tratado, buscando possibilidades de sentidos ao objeto no teatro.

Palavras-chave: Teatro, objetos, cena.

\begin{abstract}
:
The relationship between theater and the objects have long mark dates and approaches are quite distinct in relation to the dialogue between these two elements. Guided by the diversity of uses is questioned-which object is valid for the theater. Plotting a route that involves the investigation of the pedagogical and creative potential of the objects in the theater, the issues presented here pervade the perception of theater school students and the meanings of Patrice Pavis, Fernando Stratico, Ligia Clark and other authors about the subject treaty, seeking possibilities of meaning to the object in the theater.
\end{abstract}

Keywords: theater, objects, scene.

A palavra objeto designa, em diferentes áreas, distintas acepções, têm-se, por exemplo, algumas aplicações na língua portuguesa como objeto direto e indireto, já na filosofia considera-se o objeto enquanto oposição ao sujeito, no meio acadêmico utiliza-se o termo objeto de pesquisa, e em outros campos existem diversas abordagens. No que se refere ao objeto no teatro, torna-se necessário questionar: qual objeto esta é válido para o teatro?

O cerne deste questionamento foi gerado em uma oficina de teatro, ministrada na escola Liceu do Conjunto Ceará (LCC), em uma ação do Programa Institucional de Bolsa de Iniciação a Docência (PIBID) - Teatro - UFC. O corpo discente da oficina era formado por cerca de quinze estudantes, todos do LCC, tendo uma média de dezesseis anos de idade, a maioria dos alunos cursava o primeiro ano do ensino médio. 
Na tentativa de responder o questionamento suscitado, partilhando a angústia de tentar definir 'o que é objeto' com os alunos da oficina, discutiu-se e tentou-se elaborar um construto comum aos participantes sobre a compreensão de objeto referente ao trabalho em questão. Desta forma, foi solicitado que os alunos participantes da oficina supracitada que procurassem definições em diversos locais, como revistas, dicionários,, indagassem aos mais experiente ou tentassem gerar baseados em suas experiências um conceito/ideia de objeto.

A discussão gerou diversas reflexões. Existia, da parte dos alunos, um grau de exigência muito grande com a precisão da definição. O desejo era que neste conceito fosse explicitado de forma clara quais objetos seriam trabalhado, já que estes seriam transpostos para os escritos teóricos posteriormente, além, é claro, da necessidade de entendimento dos alunos com qual elemento se estaria trabalhando.

O primeiro esboço de definição foi que os objetos seriam qualquer coisa sólida, que possa ser vista ou tocada. ${ }^{1}$ Porém, esta definição era insuficiente para demarcar o elemento de trabalho desta oficina. Os alunos argumentavam que a definição não contemplava o objeto, e de fato era insuficiente, pois pela falta de especificação agregava outros elementos que não eram os objetos ao qual estava se referindo. Assim, os alunos exigiam continuar pesquisando e investigando para encontrar uma definição mais eficaz.

Pelo fato de se está reportando ao objeto em um recorte teatral geralmente se atrela este ao cenário ou aos elementos de cena. Em busca de possibilitar uma base histórica, recorreu-se a Pavis (2011, p. 265) que afirma que durante um determinado tempo o termo objeto no teatro, em alguns escritos, substituía o que se entende hoje por cenário e acessórios. Apesar de em determinadas e diversas situações em que o objeto possa se remeter a estas possibilidades e sem negligenciá-las, pode-se dizer que pensa-lo dentro da arte teatral somente nestes aspectos é raso, deixa de evidenciar diversas possibilidades de uso e aplicação. Assim, Pavis ainda expõe que o objeto extrapola esta visão que foi vigente durante muito tempo e alcança outras possibilidades. Pode- se ver que

O objeto não é reduzido a um único sentido ou nível de apreensão. O mesmo objeto é muitas vezes utilitário, simbólico, lúdico, conforme os momentos de representação e, sobretudo, conforme a perspectiva da apreensão estética. Ele funciona como um teste pro-

1 Diário de Bordo da Aluna, baseada também na definição de um minidicionário.

$2 \mathrm{O}$ teste de Rorschach é uma técnica de avaliação psicológica pictórica, comumente denominada de teste projetivo ou

IACÁ: Artes da Cena | Vol. I | n. 1 | ano 2018 
jetivo de Rorscharch, estimulando a criatividade do público. $\left[^{2}\right]$ (PAVIS, 2011, p. 266)

O objeto começa a ser percebido além de uma única acepção, alcançando outras possibilidades de percepção. Outros territórios podem ser acessados além de sua utilidade. Pavis explicita que o objeto acaba funcionando como um teste projetivo de Rorscharch, onde manchas diversas e aleatórias são colocadas para que alguém as interprete, sendo que esta leitura de imagens é feita sem preocupação em notar o objetivo de sua criação, mas percebendo o que a imagem pode propor enquanto figura,, recebendo acepções que podem fugir de sua pretensão inicial. O objeto vai além da função para que foi construído. Haveria uma infinidade de objetos dentro de um só, mesmo que estes outros estivessem ligados a sua matriz. Dentro destas possibilidades, uma das características mais importantes deste é o seu caráter sólido e ocupante de espaço, assim podendo gerar contato físico com todos os outros elementos da cena. Podendo, a partir dessa acepção se agregar mais uma característica para a definição que o grupo procurava. A ideia de objeto resultou de uma construção coletiva em que cada aluno-ator apontava as necessidades que considerava pertinente. Depois de algumas sessões de debates foi fixada a ideia de que objeto são elementos sólidos que podem ser vistos, tocados e portados. Esta ideia se tornaria um fio condutor para a realização das atividades propostas no Laboratório Cênico.

A preocupação do grupo girava em torno de designar o objeto no teatro e pensar suas diversas possibilidades cênicas. Quais seriam então estas potencialidades? O objeto poderia fugir de sua função? Tendo em vista estas diversas possibilidades que objeto opera dentro da cena, uma delas se loca em uma função pragmática, em que se resume a ser o que é, ou seja, aplicando-o sobre a sua função primária, original. Assim, Pavis (2011, p. 265) sugere sobre o objeto que "é usado para certas operações ou manipulações. Esta função pragmática é particularmente importante quando a cena mostra homens e mulheres em ocupações cotidianas". Tendo, por base esta primeira acepção de uso do objeto no teatro, sua função utilitária, que também é de grande importância, é um das potências, porém, pode-se navegar em um mar de possibilidades que fogem desta função.

O objeto acaba não só mantendo um aporte funcional, mas agrega sobre si outros cami-

2 O teste de Rorschach é uma técnica de avaliação psicológica pictórica, comumente denominada de teste projetivo ou mais recentemente de método de auto-expressão. Foi desenvolvido pelo psiquiatra suíço Hermann Rorschach. O teste consiste em dar respostas sobre com o que se parecem as dez pranchas com manchas de tinta simétricas. A partir das respostas, procura-se obter um quadro amplo da dinâmica psicológica do indivíduo. O teste de Rorschach é amplamente utilizado em vários países. 
nhos de abordagens, como o da cultura, pois todo objeto apresenta implicações na sociedade, na educação, na estética e no ser humano. Nenhum objeto é desprovido de significado, ele possui, mesmo fora de sua função, outras semânticas que podem derivar de suas relações com a sociedade, com o indivíduo ou até mesmo com outros objetos. Não opera enquanto uma folha em bran$\mathrm{co}^{3}$, apresenta outras conotações que fogem do que este é. Pavis afirma que:

Não existe objeto bruto que já não tenha sentido social e que não se integre a um sistema de valores. O objeto é consumido tanto por sua conotação quanto pro sua funcionalidade primeira. [...] De modo que ele se acha preso num circuito de sentidos (de equivalências) e remetido por conotações a uma grande quantidade de significados [...] (PAVIS, 2011, p. 266)

Ao se colocar num meio social o objeto assume diversas possibilidades, de certa forma, foge de sua função primária e agrega alternativas, inclusive poéticas. Entra em contato direto com outras variações de significação que não estão diretamente relacionadas com sua estrutura, mas com o que o objeto carrega enquanto marcas. Stratico $(2012$, p. 01) expõe sobre a capacidade de o objeto carregar marcas de seus sujeitos, de quem o fez, o utilizou e dos ambientes que passou. Torna-se um portador de memórias, inclusive afetivas. Adentra a um território de afetos em que pode carregar sobre si acepções como sagradas (objetos religiosos), pessoais (presentes ou lembranças de entes queridos), cotidianos (aqueles que são habituais), não cotidianos (que não são habituais) e outras que podem ser definidas por uma relação subjetiva individual.

Durante as discussões levantou-se a questão de que o objeto remete diretamente a objetivo. Pensando na sua materialidade, a objetividade parece ser inerente deste, pois apresenta uma estrutura física concreta. ${ }^{4}$ Tendo o teatro como uma área de conhecimento que trabalha também com a subjetividade, indaga-se: será que o objeto não extinguiria a subjetividade por sua objetividade?

As palavras objetividade e subjetividade na língua portuguesa encontram-se como antônimas, porém, no decorrer de algumas experimentações com o objeto no teatro percebeu-se que o objeto dá acesso a territórios que tocam o subjetivo. Em uma transposição poética o objeto dilata seus sentidos e significados, formas e conteúdos. Pode-se observar que Pavis reflete sobre o desligamento do objeto do mundo real, ao falar que ele funciona como:

[...] significado, o que quer dizer que sua materialidade (seu significante) e sua identidade

\footnotetext{
${ }^{3}$ Mesmo tento em vista que uma folha em branco é um objeto, utilizou-se esta para exemplificar o caráter vazio.

${ }^{4}$ Por mais que o objeto mude em forma, como é o caso do tecido ou outros objetos maleáveis, sua estrutura permanece a mesma.
} 
(seu referente) tornam-se inúteis e integram-se ao processo global da simbolização. Todo objeto posto em cena sofre esse efeito de artificialização/abstração (de semiotização), o que não ocorre sem cortá-lo do mundo real e intelectualizá-lo. (PAVIS, 2011, p.266).

Ao desconectar o objeto do mundo real, ou seja, desligá-lo de suas funções reais e criacionais, pode interligá-lo a outras conotações, aproximando-se de um mundo onírico e revelando seu lado abstrato, que sofreu alterações por uma percepção artística. No ato de colocá-lo no palco, permite-se transformar em signo, fazendo com que todas as leituras sejam possíveis tendo o teatro como lente. É apresentado por Bablet (2008, p. XL) ao falar da abordagem Katoriana, a possibilidade do objeto de despojar-se de toda sua expressividade original, encaminhando o objeto para outros alcances, fazendo com que ele desprenda-se de sua estrutura e se desestruture para se reestruturar em outros campos de possibilidade.

As funções primárias do objeto podem revelar outros lados, reorganizando a estrutura para que novas formas de percepção possam surgir, invertendo a estrutura, mas sem modificar o que é de fato estrutural. Kantor (2008, p. 141) reflete sobre o lado inverso do objeto, onde expõe ser semelhante a um espaço vazio nos arredores do zero, comparando-o ainda como uma bola inflamada e ardente as mãos, ou seja, algo que não se suporta segurar, algo que está em constante mudanças, em constante movimentação. Não exila o objeto de suas características físicas, mas observa-o enquanto potencial além das grades materiais, onde acesso pelo físico o território do pensamento, ativando o campo cultural e todas as vivências sociais. Por mais hermético e imutável que um objeto possa parecer, através de uma percepção de um fluxo cultural, do que se passa pela cultura particular de cada um, ele suscita aberturas a possibilidades.

Até para se mostrar objetivo o objeto precisa abstrair algumas características para que se possa defini-los. Por exemplo, uma cadeira, é definida enquanto tal por um determinado conjunto de características que todos os objetos que se denominam 'cadeira' possuem. Porém, existem diferente tipos de cadeira, com ou sem braços, altas ou baixas, com ou sem pernas, com apoios e outras singularidades de cada modelo. Faz-se necessário abstrair estas diferenças para que o objeto se defina enquanto tal. Esse caráter idiossincrático e singular de cada objeto também interessa e é potente, pois o peso, as cores, os materiais, a forma, a densidade e outras caraterísticas variáveis, interferem nas relações que serão estabelecidas entre ator e o objeto. Cada objeto é sempre único, no que diz respeito à relação. Por mais que existam duas cadeiras do mesmo modelo, estas são diferentes. Cada uma destas carrega suas devidas memórias e utilizações durante seus percur- 
sos.

O objeto se apresenta como elemento multifacetado, podendo acessar diversos territórios e contribuindo com todas as suas características externas e internas para a cena teatral, Pavis (2011, p. 266) afirma que "muitas vezes os objetos se veem elevados ao estatuto de plástica móvel, atuando para e com a cena, produzindo, graças a sua dimensão poética, teatral e lúdica, uma miríade de associações mentais no espectador." Distribuindo assim possibilidades para a cena teatral, afetando por sua materialidade e fazendo com que sua estrutura permita acesso a campos não materiais.

\section{Percursos estéticos dos objetos no teatro}

Ao se falar do objeto no teatro rapidamente se associa aos objetos que aparecem durante a encenação. Deter-se a esta abordagem é limitante, pois diversas são as formas de explorar o objeto na cena teatral. Alguns artistas, encenadores e teatrólogos já se utilizaram dele para desenvolver uma série de técnicas, um estilo de encenação, criação e improvisação. Os objetos estão envolvidos com o teatro desde a antiguidade clássica. Segundo Stratico (2012, p. 02) o teatro foi se construindo em base com as práticas corporais e estas mesmas estavam diretamente ligadas à relação do corpo com os objetos. Desde desta época o objeto vem se apresentando em diversas manifestações artísticas, inclusive no teatro, como uma matéria prima para a criação em diversas abordagens.

Uma das abordagens com o objeto se detém a utilizar estes para a adesão de técnicas de interpretação. Telles $(2012$, p.61) fala a respeito do treinamento feito com bastões, afirma que o ator se utiliza do objeto para adquirir domínios necessários a este ofício e que o objeto é essencial para se apropriar de elementos técnicos que são inerentes do trabalho atorial ${ }^{5}$. Nestas situações os objetos são usados como treinamento para cena, abordando como poderia ajudar o ator no palco. Não é obrigatório que o objeto entre em cena, mas ele preparara o ator ela. Funciona para a cena, mesmo sem aparecer diretamente, já que o treinamento acontece antes, no processo, e através dele pode se tomar consciência do que está sendo praticado e aplicar o conhecimento adquirido através do exercício com objetos.

\footnotetext{
${ }^{5}$ Termo utilizado por Telles no Livro Pedagogia do Teatro e o Teatro de Rua.
} 
Em outras perspectivas funciona como margeador, revelando o próprio teatro, possibilitando uma autoafirmação da linguagem para o público, como espetáculo, sua artesania cênica, enquanto ato ficcional. O uso dos objetos de formas diversas, os tempos extras-cotidiano e dilatados de seu manuseio, ou até mesmo a utilização fora de sua função primária, faz com que este assevere o teatral, ficcional, possibilitando uma percepção metalinguística nas próprias encenações.

O aspecto da ruptura com o clássico é inerente ao modernismo onde a quebra se instala. 0 objeto acompanha esta perspectiva de mudança nas artes, fazendo que o teatro atinja outros territórios sensíveis, oníricos, ou seja, rompendo com a ideia natural. Pode assumir outras dimensões no mundo teatral, que surgem a partir da quebra da função primária. A partir desta quebra atirase em outros teatros, outros campos sensíveis e territórios de subjetivação, possibilitando a ele ser membro fundante da obra artística ou se tornar a própria obra artística. No caso dos readymode o objeto que não é produzido para fins artísticos, por decisão e proposição do artista, se torna obra de arte, onde a ideia do artista se sobrepõe ao objetivo da produção. Segundo Kantor (2008, p.102) os dadaístas transformaram a ideia de obra de arte levando os objetos cotidianos aos museus.

O momento no qual os dadaístas reconheceram que esse local saudável do ato de criação (isto é, a imagem) estava muito carregado por práticas cada vez mais complicadas, uma vez que eles as ignoraram sem piedade e fizeram do próprio objeto uma obra de arte apenas pela escolha e o nome - esse momento foi uma verdadeira revolução.

Grande referente da revolução citada por Kantor foi Marcel Duchamp e o ato de levar um Urinol de louça para um museu e colocá-lo em exposição. A partir desta quebra proposta o objeto passa a ter uma nova acepção dentro das artes, onde por si só pode apresentar-se enquanto obra de arte a partir da decisão do artista. E porque não dizer que no teatro, pode-se realizar esta ação, pela decisão do ator e/ou do diretor?

Kantor foi grande referente no trabalho no teatro utilizando objetos. Vale salientar que ele iniciou sua formação artística nas artes visuais, assim, seu envolvimento com os objetos vem de uma relação com a imagem, onde a força imagética fundamenta seu trabalho. Desta forma, a imagem apresenta outras possibilidades além da semântica comum do objeto. Kantor foi um dos precursores da desnaturalização do uso dos objetos no teatro, como se pode ver 
Tomo consciência de que devo fazer alguma coisa com o objeto para que ele comece a existir, alguma coisa que não tenha nenhum laço com sua função vital; sinto que um ritual é necessário, que seja absurdo do ponto de vista da vida e que possa atrair o objeto para a esfera da arte. (KANTOR, 2008, p. 50)

A proposição de desvincular o objeto da função vital para que se aproxime da esfera da arte é ponto importante no trabalho de Kantor, assim como a transposição do objeto para um estado de proposição artística, um desencadeador de ideias, propondo relações, possibilitando novos questionamentos e se colocando como inspiração para a criação, tratando-o como potência expressiva.

Dentro das várias formas de potências expressivas, Pinto (2011, p. 1927) aponta algumas das formas que Kantor se relaciona com objeto, que remetem a utilização como material da memória individual e coletiva, ou seja, uma abordagem cultural do objeto e investigando a significação e a ressignificação dentro do espaço da cena. Deve-se ainda atentar para a possibilidade de apoderar-se dele. Kantor (2008, p. 140) diz: "quero que se apreenda o objeto, que se apodere dele, e não que se mostre ou reproduza! (Que diferença formidável!)". Mostra que o objeto deve se relacionar com os atores, com o espaço, com os espectadores e se torne propositor de manifestações, pois o fato de apenas expor o objeto não movimenta artisticamente.

Sobre ideia de os objetos provocarem movimentos artisticamente, outra investigadora propõe um trabalho, a artista plástica Lygia Clark. Também tem sua formação ligada às artes visuais, desenvolveu um trabalho denominado Bichos em 1959. "Bicho é o nome que ela [Lygia Clark] dá a estruturas geométricas móveis, de metal industrializado, presas por dobradiça que faz lembrar uma espinha dorsal." (CARVALHO, 2011, p. 133). Ela propunha neste trabalho uma interação entre obra e espectador, convidando o espectador a entrar em contato com o objeto e alterá-lo na forma que achar pertinente, era possível manipular os bichos e tornar-se um coautor da obra. O objeto aponta mais uma vez como propositor de uma relação.

Com o passar do tempo, Clark propôs uma nova intervenção, os Objetos Relacionais pensando nas características estruturais e físicas propõe um trabalho com a ativação do sensorial. Clark (1980, p. 49) afirma que:

O "objeto relacional" não tem especificidade em si... O mesmo objeto pode expressar significados diferentes para diferentes sujeitos ou para um mesmo sujeito em diferentes momentos... Formalmente ele não tem analogia com o corpo (não é ilustrativo), mas cria com ele relações através da textura, peso, tamanho, temperatura, sonoridade e movimento. 
Com os Objetos Relacionais Clark assume diversas proposições estéticas, pedagógicas e até terapêuticas. Ela classifica suas obras como proposições artísticas onde o objeto se torna um estímulo, uma potência, um fator determinante para a criação. Assim, apropriando-se de sua materialidade para propor uma estética criacional. Numa fase denominada Nostalgia do Corpo, Carvalho (2011, p.137) afirma que o objeto nos trabalhos de Clark é um meio entre o corpo e a sensação. Colocando-se num lugar de trânsito, o objeto se coloca em diálogos de aproximações e distanciamentos.

Tendo como base a criação de uma estética que é desenvolvida a partir dos objetos, diversos grupos teatrais desenvolvem trabalhos com objetos. Lecoq (2010, p. 234) cita o Nada Théâtre e Telles (2012) aponta o Grupo Cultural Yuyachkani ${ }^{6}$. Estes grupos desenvolvem criações artísticas a partir dos objetos. Em relação à epistemologia do ator, a pedagogia da cena e sua relação com os objetos pode-se utilizar como exemplo uma atividade que o Lume Teatro ${ }^{7}$ realiza:

[...] trabalhamos em nossos treinos basicamente com dois tipos de objetos: o bastão e o tecido. Um rígido, de forma fixa e imutável, e outro flexível, cuja forma é mutável. Para o treinamento com o objeto, é importante desenvolver a escuta de sua dinâmica. Cada objeto tem uma forma, uma espessura, um peso que determinam uma dinâmica muito particular se lançado no ar. (BURNIER, 2001, p. 117)

$\mathrm{Na}$ abordagem da materialidade do objeto feita pelo Lume, procura-se explorar as extremidades de classificação dos objetos. Um altera sua forma - o tecido - e outro não - o bastão. Passeando pelas possibilidades de características (peso, densidade, forma e outros) o treinamento para a cena é realizado envolvendo estes aspectos estruturais, vão despertando, através de sua ocupação de volume no espaço, bem como também, o seu comportamento durante a manipulação, um ato perceptivo no/do corpo. O praticante deste exercício relaciona-se com o objeto e atenta para ativação de estados corpóreos e também a como levar estes estados para o palco. Outras diversas possibilidades de trabalho são abertas. Stratico (2012, p. 03) afirma que "infeliz-

6 Grupo Peruano, que está relatado no Livro TELLES, Narciso. Pedagogia do Teatro e o Teatro de Rua. 2. Ed - Porta Alegre: Editora Mediação, 2012. Especificamente entre as páginas, 39 à 52.

7 O LUME é um coletivo de sete atores que se tornou referência internacional para artistas e pesquisadores no redimensionamento técnico e ético do ofício de ator. Um espaço de multiplicidade de visões que refletem as diferenças, impulsos e sonhos de cada ator. Ao longo de quase 30 anos, tornou-se conhecido em mais de 26 países, tendo atravessado quatro continentes, desenvolvendo parcerias especiais com mestres da cena artística mundial. Criou mais de 20 espetáculos e mantém 14 em repertório, com os quais atinge públicos diversos de maneiras não-convencionais. Com sede em Barão Geraldo, Distrito de Campinas (SP), o grupo difunde sua arte e metodologia por meio de oficinas, demonstrações técnicas, intercâmbios de trabalho, trocas culturais, assessorias, reflexões teóricas e projetos itinerantes, que celebram o

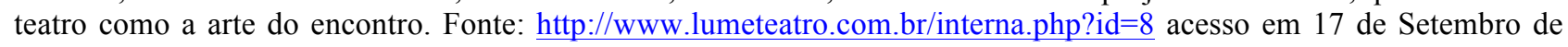
2013. 
mente não dispomos de muitos estudos sobre a presença do objeto na cena.". Andando a passos curtos e cautelosos o objeto vem ganhando espaço nas construções estéticas. Enriquecendo a cena com suas potencialidades.

\section{O objeto que nos interessa}

A aplicação e/ou o uso do objeto no teatro acontece de formas diversificadas. Desde as abordagens que têm alta importância dentro da dramaturgia do espetáculo como as que substituem algum personagem ou concretizam algum fato, há até aquelas em que eles são colocados sem nenhum propósito em cena. ${ }^{8}$ É necessário deixar claro, que o objeto no teatro só interessa se estiver em movimento, seja em movimento físico se deslocando no espaço ou em movimento ideológico/semântico se deslocando em pensamento/significado.

O objeto parado, que não realiza movimento em nenhuma das formas permanece no superficial, não adentrando a profundidade de sua potência cênica enquanto elemento pedagógico e de criação. Por mais que o movimento que ele realize seja abstrato, hermético ou não comunique a primeiro contato, a fórceps ele ínsita o pensamento, causando assim, um movimento de instigação à reflexão. Funcionando como se sua movimentação resultasse em uma onda e esta atingisse os espectadores, causando com isto, mesmo sem pretensão ou percepção, que a interrogação mova-se nos corpos e no cérebro dos espectadores.

O objeto não deve se tornar um simples enfeite de cena, como Jacques Lecoq (2010, p. 176) afirma que "o objeto aqui, nunca é um simples acessório, ele permite o desenvolvimento de um imaginário muito forte." Ele desperta estes fatores imagéticos, imaginários e sensoriais, e não se configura como um elemento subordinado, suplementar, complementar ou adorno, tendo em si uma potência própria. Abolindo a ideia de acessório e afirmando a ideia de assessório, no sentido de assessorar, dar suporte a algo, vendo-o além do que é.

O caráter de acessório ou reprodutor de determinada ação, não está sendo descriminado, porém, uso exacerbado e exclusivo deste caráter faz com que se limite à uma jaula pequeníssima ao lado de um campo vastíssimo onde se poderia passear e brincar de diversas formas sem ter

\footnotetext{
${ }^{8}$ Fato comum no Teatro não-profissional, tendo em vista que por vezes o objeto é colocado somente como enfeite ou sem um propósito estético.
} 
compromisso com o real, sem recriminação à loucura de não ser utilitário. Olhar para uma só dimensão, uma só perspectiva faz com que seja usada na cena somente a parte externa do objeto, não permitindo que este instale dúvidas, questionamentos e indagações. A interrogação é de extrema importância, pois aponta caminhos e possíveis respostas, terrenos, para onde se pode experimentar diversamente.

A favor de um objeto desencadeador do questionamento, pode-se refletir que estes elementos ao invés de nos darem respostas nos lançam em interrogações, fazem com que se possa experienciar algo, mesmo que seja para dizer não. Mostrando a importância da instalação da dúvida como ponto de partida para criação pode-se observar o que diz Ryngaert $(2009$, p. 225) "Sou a favor da pedagogia da prospecção, do tateio, da interrogação, e não a favor de um ensino de certezas". Assim, o objeto se configura como um elemento que possibilita este investigar com as próprias mãos.

Pode-se perceber na perspectiva artístico-pedagógica em que Telles (2012, p. 52) cita as possibilidades do treinamento com o objeto no teatro, e assim, observando como estes podem operar no trabalho de ator e da cena. E este objeto é o que interessa! Um elemento que funcione como agenciador de experiências estético-teatrais, como a assimilação de habilidades da cena, a criação de signos e a experimentação corpóreo-vocal-espacial, gerando matrizes oriundas de sua materialidade e imaterialidade. Levando em conta o quanto o objeto é ao mesmo tempo objetivo e subjetivo, preso e liberto, casual e planejado, caótico e organizado. Sobre estes aspectos dicotômicos do objeto Kantor (2008, p. 52) afirma que:

\footnotetext{
O objeto sempre me interessou. Eu me dei conta que somente ele é inapreensível e inacessível. [...] E o objeto continua a existir, longínquo e estranho. Não haverá meio de fazêlo "aparecer" de outra maneira? Pelo negativo, ou ocultando-o - por alguma coisa que o ocultasse.
}

Essas diversas possibilidades apontadas trazem o objeto para um campo em que sua inércia é condenada. O objeto na cena precisa de razão para estar, para viver na cena. Não pode ser simplesmente um objeto de teatro, pois a palavra de remente apenas a uma subserviência. Ele precisa ser um objeto em teatro, pressupondo um diálogo entre os atuantes, inclusive o espectador mesmo que de uma forma indireta.

Acontecendo assim, nos encontros de criação uma espécie de Laboratório Cênico, um ateliê em que a experimentação da cena seja regada por isso. Poderia ainda, fazendo um jogo de pa- 
lavras, substituir laboratório por labirinto cênico, onde somente se sabe o ponto de partida e no percurso perder-se diversas vezes sem saber quando e de que forma se chegará ao final, perdendo-se na experimentação com o objeto. O objeto que nos interessa é o que oferece relação, que oferece diálogo, que propõe e recebe propostas, que se movimenta físico e ideologicamente.

\section{Referências}

BABLET, Denis. 0 jogo teatral e seus parceiros. In: KANTOR, Tadeusz. $\mathbf{O}$ teatro da morte. São Paulo: Perspectiva, Edições SESC SP, 2008.

BURNIER, Luís Otávio. A arte do Ator: da técnica à representação. Campinas: Editora da Unicamp, 2001.

CLARCK, Lygia. Lygia Clarck. Textos de Lygia Clarck, Ferreira Gullar e Mário Pedrosa. Rio de Janeiro: FUNARTE, 1980.

KANTOR, Tadeusz. O teatro da morte. São Paulo: Perspectiva, Edições SESC SP, 2008.

LECOQ, Jacques. O corpo poético: uma pedagogia da criação teatral. São Paulo: Editora Senac São Paulo, Edições SESC SP, 2010.

PAVIS, Patrice. Dicionário de Teatro. São Paulo: Perspectiva, 2011.

PINTO, Luiz Matricardi de Freitas. A imagem e a relação do ator com os objetos: a composição de cenas na obra de Tadeusz Kantor. Anais do III Encontro Nacionais de Estudos da Imagem - ENEIMAGEM. Londrina, $2011 . \quad$ Disponível em: http://www.uel.br/eventos/eneimagem/anais2011/trabalhos/pdf/Luciano\%20Matricardi\%20de\% 20Freitas\%20Pinto.pdf (acesso em 11 de dezembro de 2013).

RYNGAERT, Jean-Pierre. Jogar, representar: práticas dramáticas e formação. São Paulo: Cosac Naify, 2009.

STRATICO, Fernando A. O objeto na cena contemporânea. Anais do XXI da Conferência da Federação dos Arte-educadores do Brasil - CONFAEB. São Luiz, 2012. Disponível em: http://www.faeb.com.br/livro/Comunicacoes/o\%20objeto\%20e\%20a\%20cena\%20contemporanea .pdf (acesso em 11 de dezembro de 2013).

TELLES, Narciso. Pedagogia do Teatro e o Teatro de Rua. Porto Alegre: Mediação, 2012.

Artigo submetido em 18/07/2016, e aceito em 11/03/2017. 